\title{
Enhancing customer satisfaction for health services
}

Deepa Rajamani

Saumya RamaRao

Population Council

Follow this and additional works at: https://knowledgecommons.popcouncil.org/departments_sbsr-rh

Part of the Demography, Population, and Ecology Commons, Family, Life Course, and Society Commons, International Public Health Commons, and the Women's Health Commons How does access to this work benefit you? Let us know!

\section{Recommended Citation}

Rajamani, Deepa and Saumya RamaRao. 2019. "Enhancing customer satisfaction for health services." New York: Population Council. 


\section{ENHANCING CUSTOMER SATISFACTION FOR HEALTH SERVICES}

Deepa Rajamani

Saumya RamaRao 


\section{Population
council \\ Ideas. Evidence. Impact.}

The Population Council confronts critical health and development issues-from stopping the spread of HIV to improving reproductive health and ensuring that young people lead full and productive lives. Through biomedical, social science, and public health research in 50 countries, we work with our partners to deliver solutions that lead to more effective policies, programs, and technologies that improve lives around the world. Established in 1952 and headquartered in New York, the Council is a nongovernmental, nonprofit organization governed by an international board of trustees.

\section{Population Council}

1 Dag Hammarskjold Plaza

New York, NY 10017

USA

Tel: +12123390500

Fax: +12127556052

email: pubinfo@popcouncil.org

popcouncil.org

Suggested citation: Rajamani, Deepa and Saumya RamaRao. 2019. "Enhancing customer satisfaction for health services." New York: Population Council.

(C) 2019 The Population Council, Inc. 


\section{Table of Contents}

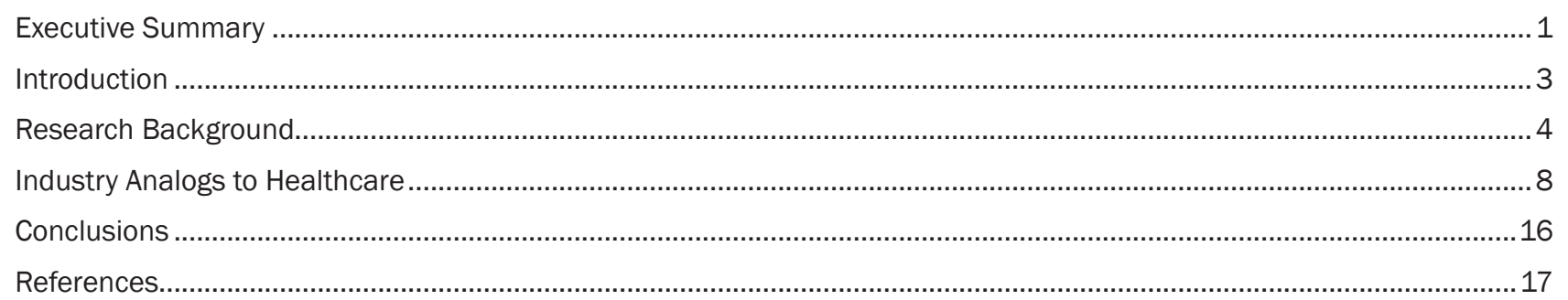




\section{Acknowledgments}

This report has been prepared by Deepa Rajamani and Saumya RamaRao under the Family Planning (FP) 2020 project funded by a grant to the Population Council from the David and Lucile Packard Foundation. We gratefully acknowledge the Packard Foundation's support and encouragement for continuing research on the current state of quality of care. 


\section{Executive Summary}

Family Planning (FP) 2020 global partnership has achieved significant gains since its inception and while it strives to accelerate uptake of voluntary FP services, women in developing countries continue to face an unmet need for modern contraceptive services. Critical opportunities for action exist in the area of understanding the effects of quality of family planning services and continued contraceptive use. Measuring and tracking the quality of FP services is an important aspect of improving service delivery and client feedback also offers critical insight into the design of demand generation and uptake strategies for a contraceptive. The goal of client-centered family planning services is to offer rights-based care that enables clients to choose a contraceptive, continue use and return to the facility for follow-up or switch products. To achieve these, clients' needs and preferences should be clearly understood by implementing a standardized approach to measuring quality of care. While a number of tools exist currently to track client satisfaction, their effectiveness and consistency have room for improvement. FP2020 partners have prioritized the engagement of the private sector as a critical strategy for accelerating progress towards these goals. By studying the market-based approaches used by the private sector to measure and improve client satisfaction, we can adopt best practices for implementing within the health services sector. In this report, we present a literature review on the current trends in customer feedback management in the private sector, particularly, industries that closely resemble the health services sector. One trend that is successfully implemented in the private services sector includes Customer Experience (CX) management. It is defined as the practice of designing and reacting to customer interactions to meet or exceed their expectations and, thus, increase their satisfaction, loyalty and advocacy. ${ }^{1}$ Further, we delve into the various quality measures that are used by service businesses to track client satisfaction. We also explore the challenges faced by these businesses with increased social media use and the innovative ways in which they are designing solutions to address these challenges. We believe that the well-tested business principles that drive success in the services business can be effectively used to scale solutions to address client satisfaction in the global health sector.

In our attempt to emulate best practices from industries that are analogous to healthcare, we find close operational similarities with the airline and hospitality industries. Just like healthcare, they are highly service-oriented, have multiple service touch points with the client, and prioritize safety, efficacy and loyalty in their service delivery. The in-depth study of customer service management in these two industries reveals existing as well as evolving trends to track customer feedback, especially with the rising use of social media across the globe. Our research offers the following three key takeaways for the health services sector to ponder:

\section{Using a $\mathrm{CX}$ approach to measure client satisfaction} in health services can offer additional dimensions of quality assessment that may be lacking in current monitoring efforts. The focus on designing interactions at every touch point offers opportunities to capture client feedback at various steps during their visit (via an 'experience' survey) as opposed to an exit survey that records responses when the client exits the facility.

2. Empowering providers with a quality mindset by giving them more decision-making power to design and deliver quality services. Further, improving patient experience increases provider satisfaction, and in turn improves their retention rates. Providers should be coached to offer customized client experience as much as possible to attract new clients and retain the existing clients.

3. Leveraging data and technology to engage clients at every patient touch point to obtain detailed experience measures, including various interpersonal aspects of care. Also, the burgeoning use of internet and social

\footnotetext{
${ }^{1}$ As defined by Gartner, Inc; www.gartner.com
} 
media channels in the developing countries offers a wide-ranging platform to access young clients who are more vocal about expressing their needs online.

Future extensions of this research are manifold, both in terms of understanding feasibility of implementation along with the inherent limitations and applicability in the settings of interest. Limitations in the form of funds shortages, lack of appropriate training infrastructure, overworked staff and the associated burnout, to name a few, can present themselves as barriers to successful implementation in resource constrained settings. Further, any new concept takes time to grasp and consistency is key to realize the desired change. Investment of time, effort and money can be key in the initial years to create long lasting impact. 


\section{Introduction}

In the seven years since the first London Summit on Family Planning in 2012, substantial progress has been made towards increasing access to contraceptive information and services in LMICs. It has been estimated that more than 82 million pregnancies, 25 million unsafe abortions, and 125,000 maternal deaths are averted every year directly as a result of this initiative. However, much work remains to be done and as of 2017, there are 214 million women of reproductive age in developing countries that continue to experience an unmet need for modern contraception. The proportion of women aged 15-49 whose need for family planning is satisfied with modern contraception is $49 \%$ in low-income countries, 69\% in lower-middle-income countries (LMICs) and 86\% in upper-middle-income countries (Guttmacher Institute, 2017). Consequently, contraceptive discontinuation remains a key measurable outcome of interest to stakeholders that finance and implement family planning (FP) programs in the developing world. Recently, Population Council, along with other partners including the WHO, UK Aid, and STEP-UP co-published a series of evidence briefs that provide decisive data on the work that needs to be done to further improve contraceptive services and uptake. ${ }^{2}$ Among other priorities, the briefs highlight the focus on contraceptive needs of adolescents, rights-based family planning in LMICs, collaboration across sectors, and expanding contraceptive choice. While exploring opportunities for action, we come across evidence that suggest that the quality of family planning (FP) services can impact continued contraceptive use (Ali, 2001; Arends-Kuenning and Kessy, 2007; Mensch et al., 1996; RamaRao et al., 2003). Studying the finer aspects of quality of care that are correlated with contraceptive method discontinuation can provide actionable insights on increasing client satisfaction and effectively help close the gap on unmet need.

The assessment of quality of care (QoC) in FP programs has been largely guided by the Bruce family planning QoC framework for the past several decades. This client-centered framework articulates six fundamental domains of quality: choice of methods, information given to clients, providers' technical competence, interpersonal relations, follow-up mechanisms and having an appropriate constellation of services (Bruce, 1990). The framework was revised recently by Jain and Hardee and it aligns with definitions of quality pertaining to rights-based approaches to health, reproductive health, and family planning (Jain and Hardee, 2018). The revised framework was also intended to help identify gaps and develop standard metrics to measure various elements of quality at structure and process levels.

Over the years, a number of tools have been developed and used to evaluate FP quality and yet there is room for improvement in the utility of existing tools for measuring and acting on client feedback in these settings (Tumlinson, 2016). For example, large scale facility surveys, such as the Service Availability and Readiness Assessment (SARA) used by the World Health Organization (WHO) and the Service Provision Assessments (SPA) of the DHS program for health facility assessment in LMICs, typically focus more on facility audits that assess infrastructure and readiness for choice. While they do collect information on client satisfaction by asking questions related to provider consultation, wait times, and the facility cleanliness, they do not capture the "unexpressed" desires of the clients that can help improve service provision and therefore make them more loyal to seek these services.

As global health stakeholders look for increased engagement with the private sector and progressively adopt market-based approaches, one key area of learning for improving client satisfaction might come from the best practices demonstrated by service-oriented private companies. Customer satisfaction is a widely pursued metric in the private sector and rigorous management approaches have evolved around the study of measuring and improving customer satisfaction. It not only serves as the primary indicator to measure customer loyalty, reduce churn rate, ${ }^{3}$ and increase revenue, but also acts as a key differentiator that helps attract new customers in competitive business environments.

\footnotetext{
${ }^{2}$ Source: https://www.who.int/reproductivehealth/publications/family_planning/policybriefs/en/

${ }^{3}$ The churn rate, also known as the rate of attrition, is most commonly known as the percentage of customers who discontinue their use of the product/service within a given time period.
} 


\section{Research Background}

Customer satisfaction is a key performance indicator (KPI) that drives quality and profitability in the service industry. One of the principal ways it is measured is via customer feedback. Customer feedback is defined as customer communication concerning a product or a service (Erickson and Eckrich, 2001). This feedback can be either solicited or unsolicited (Berry and Parasuraman, 1997). Solicited feedback is initiated by the organization using tools such as surveys and focus groups that invite customers to give feedback (Sampson, 1996). However, unsolicited customer feedback arises from the customer's own desire to communicate his/ her experiences (Sampson, 1996). Unsolicited customer feedback is also manifested through 'Word of Mouth' and it has taken on many forms with the advent of social media. With the rise of internet usage, managing customer experiences is critical because a customer review that spreads and goes viral can enhance or tarnish the reputation of a product or service. According to a survey by Gartner, ${ }^{4} 13 \%$ of unsatisfied customers will tell 15 or even more people that they are unhappy with the product or service they had purchased. However, $72 \%$ of happy customers will pass on a good word to 6 or more people. These findings highlight the increased need to provide consistently good quality service to customers in order to retain them.

Within the context of health services, Quality of Care (QoC) has been a subject of increasing interest to health care providers and organizations that finance health services. Specifically, in the area of family planning, QoC is a key driver of contraceptive use and demand generation (RamaRao et al., 2003). While we acknowledge that system readiness and clinical quality are critical factors in service delivery, it is becoming increasingly important to factor in the overall client experience when they seek FP services. It has been shown that positive patient experience in health facilities is also directly correlated with a rise in contraceptive continuation rates as well as product uptake (RamaRao et al., 2003).

Several assessment techniques such as client focus groups, in-depth interviews (IDIs), exit interviews, and mystery clients have been traditionally used to assess quality in FP clinics. These techniques typically focus on gathering clients' feedback after care delivery. Client satisfaction depends not only on the effectiveness of the contraceptive they are seeking but also the overall way in which they experience care delivery at the FP centers - down to interaction with providers, privacy, and wait time, to name a few.

The research presented here focuses on understanding the elements that constitute clients' quality expectations and their satisfaction by tracking their experience though the process of care delivery.

Mapping the client's journey in these facilities to understand their various touch points can help us gather feedback at these points of interaction to arrive at a reliable customer satisfaction metric, that not only depends on product effectiveness but also incorporates the 'voice of the client'. This approach mirrors the recent management trend employed by private companies, referred to as Customer Experience (CX) Model (as shown in Figure 1), that is driving increased business investment in the service and product industries alike, to enhance customer loyalty and retention. Here, we attempt to explore the model and the best practices from these industries for implementation in the health services sector to effectively address the end goals of client adherence, engagement, and advocacy.

\section{Customer Experience (CX) Model}

Conventionally, private sector marketers have relied upon a generalized "Marketing funnel" approach (as shown in Fig. 2) to map their customers' journey as they navigate the stages from product awareness to purchase and then towards loyalty. As consumers get more empowered with the use of technology, businesses are increasingly focusing on not only the quality of the products they deliver but how they deliver them to their customers. A new discipline around the concept of offering value via a superior 'Customer Experience (CX)' is proving to be a sustainable source of competitive advantage among businesses. ${ }^{5}$ It has been noted that

\footnotetext{
${ }^{4}$ Annual Survey by Gartner: Customer Experience for Executives, Kolsky, 2019

${ }^{5}$ Source: Results from the 2017 Gartner 'Customer Experience in Marketing' Survey.
} 


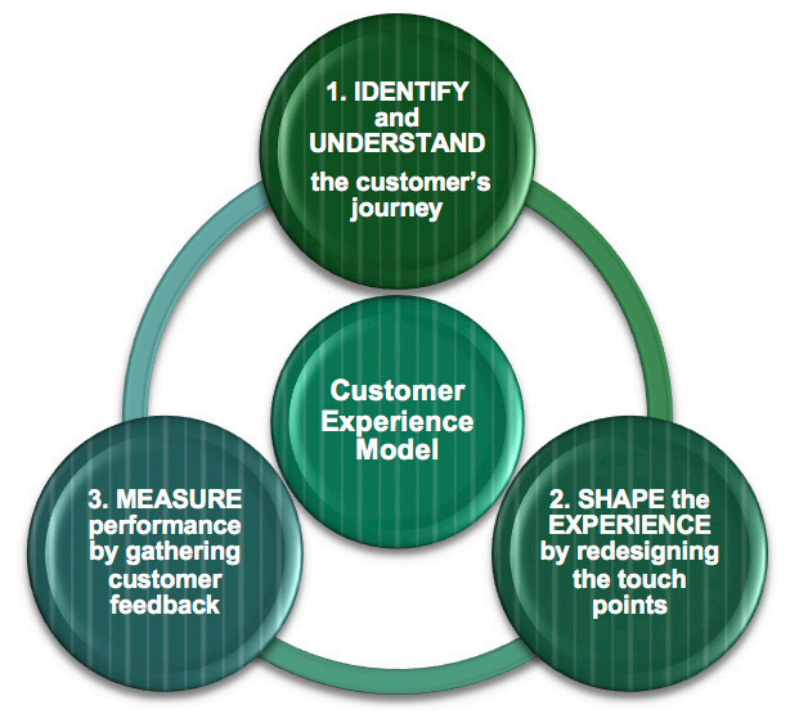

service-oriented industries such as airline and hospitality, that thrive on attracting new customers and retaining them by offering better value at every step, benefit greatly from the CX approach. CX serves as a more accurate and holistic measure of customer satisfaction.

The implementation of the CX model aims to:

1. Identify and understand the customer's journey: Customer journey is a framework that allows a company to trace the journey that a potential customer undertakes as they seek a new product or service. It enables companies to be more cognizant of their customers' needs and their pain points and be responsive by mobilizing employees to deliver value to them consistently. For example, Healthcare companies, mainly, pharmaceuticals, are increasingly focusing on developing their strategies based on the "customer decision journey" or patient journey mapping to track their touch points and using technology-based solutions to engage with them. The digital patient journey mapping is done by using a CareFlow exhibit (as shown in Fig. 3). The typical journey starts when the patient detects a health issue, does research about the issue, consults with healthcare providers, deliberates on the cost of treatment, fills a prescription, experiences side effects, considers alternatives, and either continues or stops treatment. Each of these points offers an opportunity for pharma-

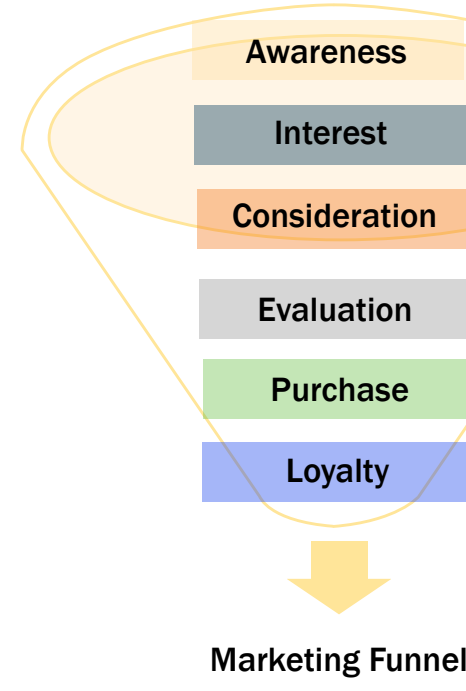

ceutical companies to engage the patient by providing education, supporting their decision, or offering remedial measures.

2. Shape the experience by redesigning the various touch points along the journey: Research suggests that it is possible to drive up customer perceptions and satisfaction levels (Chase and Dasu, 2013). Companies can score high on satisfaction by designing a sequence of interactions with customers to end on a positive note. ${ }^{6}$ For example, healthcare providers can enhance customer-journey experiences by merging multiple back and forth interactions, that might otherwise be redundant and attribute to delays and lengthy wait times, to diminish their perceived duration and create a feeling of progress. Further, the use of "soft" behavioral psychology techniques to shape the journey can help to create positive outcomes. For instance, by introducing options that give customers a feeling of control and choice as they navigate the system, they can experience a positive journey.

3. Measure performance by gathering customer feedback to assess value generated: To monitor the value generated as a result of implementing the CX approach, it is critical to measure the effectiveness of customer feedback continuously and introduce changes as needed. This is achieved by (a) linking value creation

\footnotetext{
${ }^{6}$ See John DeVine and Keith Gilson. 2010. “Using behavioral science to improve the customer experience,” February 2010, www.McKinsey.com.
} 


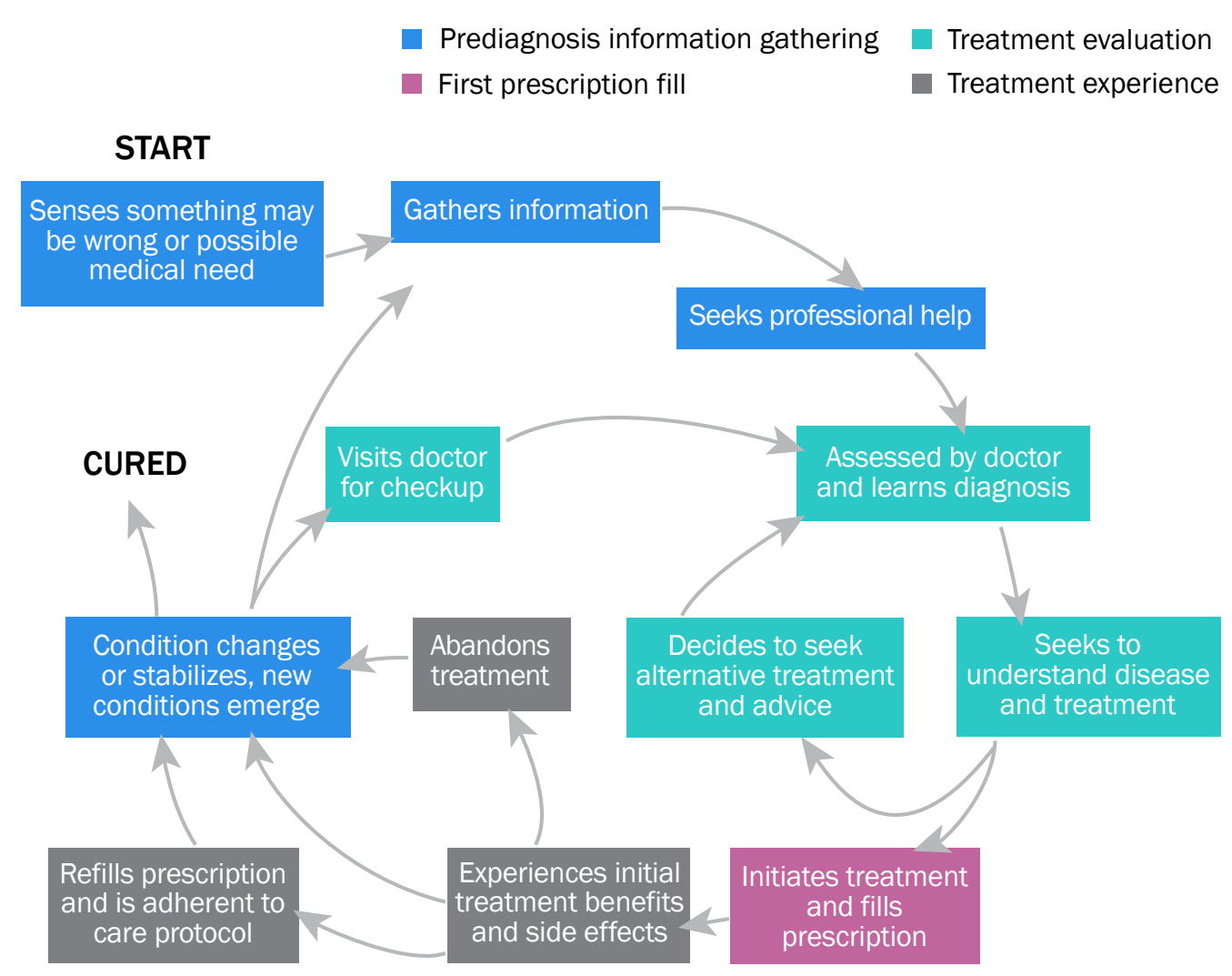

Source: Pharma3D.com; McKinsey analysis

to the outcomes that really matter (revenues, industry leadership, to name a few), (b) by analyzing historical performance of satisfied/dissatisfied customers and, (c) by focusing on the ways to alleviate most critical customer pain points. For instance, health facilities that prioritize client adherence can create value by identifying the changes that are easy-to-implement but offer high levels of payoffs. In doing so, they can achieve their goals of increased client satisfaction in a quick and efficient manner. Further, by maintaining and analyzing historical data, they can understand the evolution of their clients' needs and realign their service delivery strategies accordingly.

\section{Customer Satisfaction Metrics}

Private sector businesses use various metrics to track and measure customer satisfaction. These metrics when used in conjunction with other data gathered from various touch points with the customer offer a holistic measure of CX. Favorable CX metrics in turn translate to increased customer loyalty, retention and profitability. Some well-known metrics include (a) Net Promoter Score (NPS), (b) Customer Satisfaction (CSAT), and (c) Customer Effort Score (CES).

(a) Net Promoter Score (NPS) surveys contain one important question: "On a scale of 0 to 10 , how likely are you to recommend us to a friend?" A score of 9 or 10 indicates a strong customer who is very likely to promote the product or service, 7 or 8 indicates a passive customer and 6 to 0 are the unhappy detractors. Usually, an open-ended follow-up question is also asked: "Could you please tell us why?" This qualitative feedback can be used to guide improvement efforts from product design to service design and delivery. NPS is a valuable tool for measuring not just customer experience, but also customer loyalty, as it draws on their collective association with the company. Therefore, it serves as a good indicator for product repurchase, strong brand relationship and the company's future growth.

(b) Customer Satisfaction Score (CSAT) is used when the goal is to measure feedback at specific touch points 
or transactions along the customer's journey. A CSAT survey asks a customer how satisfied they are with a recent interaction-often a purchase or a customer service call-on a rating scale. While NPS is a high-level metric, CSAT is flexible and highly customizable - the survey can be made long or short and the responses averaged to obtain a composite CSAT score. An open-ended follow up question allows customers to describe what attributes of satisfaction are working/ not working for them. The additional benefit of CSAT surveys is that it can be used to test the effectiveness of an interaction with support staff for example, it can identify agents who may need more training, or quantify the impact of a new training effort.

(c) Customer Effort Score (CES) surveys are designed under the premise that for superior service or support, "effortlessness" is the most suitable measure of customer satisfaction. The survey asks the customer, "How much effort did you have to expend to handle your request?" and is scored on a numeric scale. It is predominantly used to improve customer service systems that can cause frustration to the customer and attrition, as a result. The CES survey helps identify pain points for the customer and problem-solve in a timely manner.

While NPS addresses the big picture of customer loyalty and long-term brand relationship, CSAT \& CES are focused on the individual transactional aspect of the experience. By honing in on one customer attribute, CES is incredibly useful in gaging customers' desired outcome. On the other hand, CSAT can measure overall satisfaction on several attributes and help us isolate those that are most meaningful to our customers. Together, these metrics offer a multi-layered approach to measuring and tracking $\mathrm{CX}$. 


\section{Industry Analogs to Healthcare}

In our attempt to emulate best practices from industries that are analogous to healthcare, we find that parallels can be drawn from the airline and hospitality industries. Both are traditionally service-oriented and have multiple service touch points with the customer. Within the airline and healthcare realms, the obvious similarities lie in the aspect around safety and risk assessments that are paramount to service delivery (Thomas and Helmreich, 2002; Gordon et al., 2013). Customers in both these industries implicitly expect high levels of safety, efficacy and quality, while trusting their lives with these service providers. Passengers expect pilots and the planes to operate flawlessly, to get them safely to their intended destination. Patients expect healthcare providers to treat them accurately and effectively and nurse them back to good health. There is very low tolerance for error in both these settings.

Over the years, health care providers have learned several lessons from the airline industry with regards to implementing crew resource management and checklists (Clay-Williams and Colligan, 2015). However, one area where rich lessons could be learned from lies in customer satisfaction. From a client's point of view, the experience of flying (see Fig. 4 for a typical customer journey map of an airline passenger) and seeing a health care provider are similarthe wait times, restricted entry points, complete handover of trust to the pilot/provider, anxiety associated with the actual experience of flying/clinical exam, and the inherent power and knowledge differential between pilot/provider and the client, to name a few. These similarities offer a right platform to explore and implement customer experience management lessons from airlines to health services.

In a similar vein, hotels and hospitals share many core operational attributes (see Fig. 5 for a typical customer journey map of a hotel guest). First, the focus is on creating positive experience/outcomes for their guests/patients, respectively. Second, there is a wide variation in service offerings: hotels vary based on target markets (Business, Airport, Vacation rentals), size (under 200 rooms to over 700 ), levels of service (distinguished by star ratings to indicate upscale quality, additional amenities and comfort), and ownership (Single-owned to large Chain hotels); hospitals vary along the same dimensions - in size, setting, services
FIGURE 4. Airline Customer Journey Map

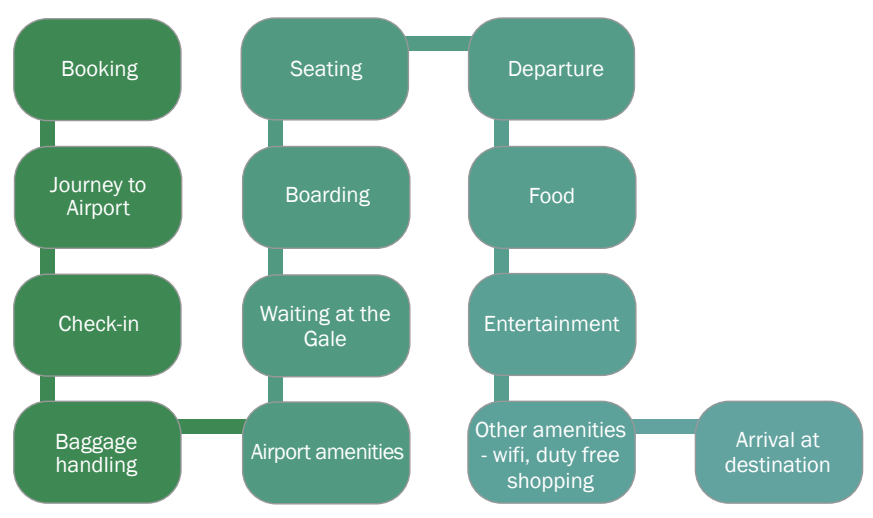

FIGURE 5. Hotel Customer Journey Map

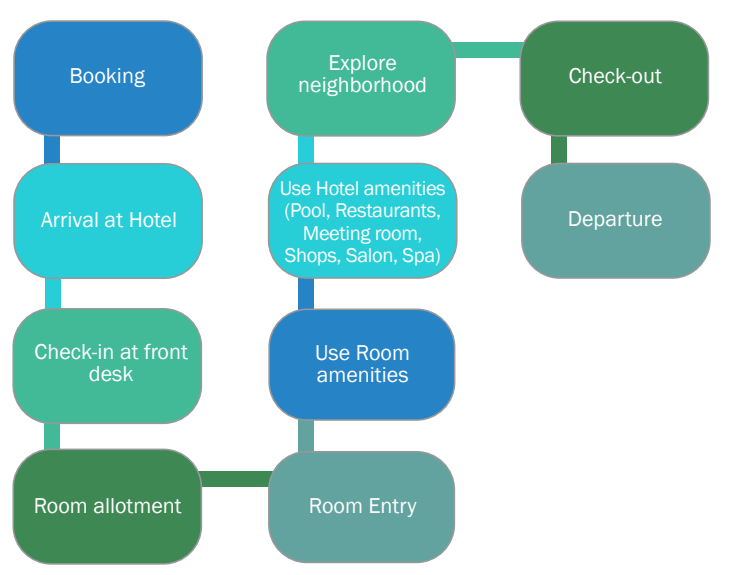

offered, and quality. Both employ a large hierarchy of workers with varying levels of skills and responsibility. While both industries cater to increasingly well-informed clients and a competitive marketplace where quality drives profitability, there has been little cross-over in terms of best practice sharing between them. Hotels place high importance on not only satisfying their guests but exceeding their expectations and use significant investment to improve their management systems consistently. The use of rigorous management approaches and continuous market research have led to widespread innovations that strive to improve customer satisfaction in the hotel industry. While the primary goal of health services is to improve patient health, patient comfort and experience should not be neglected along the way. To that end, healthcare would immensely benefit from studying and adopting the customer feedback models utilized in the hotel industry. 


\section{Industry Analog 1: Spotlight on Airline Industry}

Traditionally, airline industry has relied on utilizing standard surveys via the most common customer feedback channels available, namely: suggestion boxes, telephone/mobile, personal emails and website to gather customer feedback. ${ }^{7}$ Fig 6 shows a typical feedback form used on an airline's website. To distinguish themselves by offering better value in a highly competitive market, most airlines are now trying to implement an omni-channel customer service approach to collecting and analyzing customer feedback and acting on them in a timely manner. Omni-channel customer service consists of numerous interactions across multiple touch points between a customer (or prospective customer), and product or service provider during the time of sale, and throughout the customer lifecycle. In other words, it means allowing customers to access the company's services on any platform and experience seamless interactions, regardless of the various channels (or devices) they choose. Most airlines maintain points of interactions with the customer, for example at the booking process, the check-in, the boarding and the in-flight experience itself, and arrival at destination. Using data collected at every touch point, namely seat preferences, diet restrictions and commonly flown routes, they can aim to exceed their customers' expectations (Clayton and Hilz, 2015). While there is always a risk of losing customers (also referred to as churn), periodically following their interactions and analyzing their feedback can help enhance customer loyalty and retention.

In recent years, the airline industry has been fraught with unpleasant stories with regards to customer service. For instance, Ryanair canceled its flights, affecting 300,000 to 400,000 customers due to errors when scheduling the holidays of their pilots, and United Airlines dragged a passenger off a flight because his seat was to be given to a crew member, all of which demonstrate serious lapses in customer centric behavior. These negative instances not only affect individual customers but create a ripple effect in the way other potential customers could perceive service quality of these airlines.

According to a recent survey conducted by Clarabridge, ${ }^{8}$ crew attitude is the primary driver of customer loyalty. In the U.S., 38 percent of customers are loyal to an airline based on how they are treated, closely followed by 35 percent of customers who choose based on price. 33 percent of all UK customers recommended an airline to their friends only based on how friendly they perceived the crew to be. The survey results suggest that while various reasons attribute to poor customer service behavior including crew burnout, below par incentive systems, inadequate training, to name a few, fixing these issues could positively benefit the airlines in acquiring more customers.

The survey results further indicate that in both countries, customers expressed a preference for digital feedback. Of those that provide feedback, 46 percent and 42 percent in the U.K. and U.S. do so by email, and 13 percent and 11 percent, respectively, by social media. More than half of all customers utilize digital tools to comment on their experience. In conjunction with an increase in digital feedback, the survey data suggests that airlines must increase investment in the technical infrastructure necessary to support customer complaints.

Considering these recent trends, while most airlines have responded effectively to the demanding marketplace by investing in technology, the explosion of social media poses a significant and growing challenge for the industry. With Twitter, Facebook, Yelp, Instagram and other Social media channels serving as strong customer opinion platforms, more unsolicited feedback channels must be monitored in order to implement improvements and increase customer satisfaction. Strong feedback management can empower airlines to identify and address the root cause of customer complaints faster and prevent one negative interaction from potentially going viral. Whether at check-in or the post-flight survey, dynamic data collection tools can help monitor and optimize the flying experience at every touch point and on every channel. From product surveys to suggestion boxes and call transcripts, every point offers an opportunity to gather customers' voice that can potentially feed into service delivery strategies.

JetBlue Airways provides a good example of how a company can successfully use social media to better connect with its customers. In 2007, the company came last in terms of American customer satisfaction ratings because of an incident that led to about 1,000 flight cancelations within five days, stranding thousands of passengers. However, with

\footnotetext{
${ }^{7}$ Source: Websites of major carriers (United Airlines, Emirates, British Airways)

${ }^{8}$ Source: Clarabridge Report: Customer Experience in the clouds: A look at today's air traveler expectations, 2017; prepared by: LaunchSquad
} 
clever use of social media it began to turn things around within a matter of four years. At the core of this campaign was an unscripted YouTube video, where the company's CEO Neeleman, apologized for the airline's mistakes and announced a "Customer Bill of Rights," which outlined remedial steps the airline would take to address service interruptions. This video received a significant number of positive comments. The recognition of just how effective social media can be in reaching its customers made them craft an overall social media marketing strategy. The key piece of this strategy included JetBlue's Twitter account, which grew from a mere 700 followers, to approximately 1.1 million in just two years. Today, on average, JetBlue gains 4,000 followers per month and posts an average of four tweets per day. ${ }^{9}$ This kind of growth can be directly attributed to the company's social media strategy of effectively using Twitter to gage their customers' opinion of them, responding to their questions and finally engaging in full blown conversations with them.

In slightly over four years, JetBlue made enormous strides in improving its relationships with its customer base using social media. As of the end of October 2011, the airline's YouTube Channel had accumulated over a million views. Its Twitter page had attracted over 1.6 million followers, with more than 12,000 tweets and its Facebook page raked over 500,000 fans. The effective use of social and digital media continues to play a key role in helping the company strengthen its brand. By listening to its customers and acting on their feedback, the airline now enjoys a loyal customer base. ${ }^{10}$

\section{Industry Analog 2: Spotlight on Hospitality Industry}

In the hospitality industry, the main 'product' of interest to the customers is the actual 'experience' created by these businesses for their customers. For a customer looking for a lodging service, the whole experience encompasses booking, check-in process, room selection, room service, food and other amenities offered by the hotel, and other nuanced aspects related to the stay that can deem the overall stay enjoyable. In this context, customer loyalty is a product of overall satisfaction arising from service, quality and price. Therefore, to retain its customers, hotels must create tailored guest experiences. According to Forrester Research, a one-point improvement in the customer experience score for upscale hotels produces $\$ 6.52$ per customer in additional revenue. ${ }^{11}$ This translates to the fact that more satisfied guests tend to stay loyal and do not mind paying a premium for the superior experience. ${ }^{12}$ However, the definition of what constitutes superior experience is ever changing and hotels have constantly worked towards capturing the changing needs of their customers by efficiently integrating customer feedback mechanisms into the way they serve their customers.

Gallup's 2014 Hospitality Industry study analyzed six distinct segments of the hotel market -- luxury, upper upscale, upscale, upper midscale, midscale, and economy -- to uncover the needs and expectations of hotel guests across these segments. The study revealed that economy customers are least likely to strongly agree that the hotel they visit most frequently cares for their well-being (15\%), while the percentage doubles for luxury hotel customers (31\%). Luxury brands were found to have the highest customer engagement level of all hotel segments, with $33 \%$ of luxury guests being fully engaged in a brand (79\% of guests who strongly agree that the hotel they visit most frequently takes care of their well-being, are considered to be fully engaged). The link between well-being and engagement is very critical to the profitability of these businesses as engagement serves as a strong predictor of business growth.

Further, Gallup's analysis shows a strong correlation between customers' engagement levels and the amount of money they spend per visit. Guests spent an average of $\$ 457$ per stay at the hotel they visited most frequently in the past 12 months, but fully engaged guests spent $\$ 588$ per stay compared with $\$ 403$ per stay for actively disengaged guests -- a difference of $\$ 185$ per customer. Therefore, hotels are finding innovative ways to achieve higher levels of customer engagement. For example, the Zighy Bay Resort in Oman gives guests the option to paraglide into the resort on arrival, in Sweden guests can stay in an Ice Hotel and Club Med offers a Cirque du Soleil experience. Additionally, engaged guests are also found to be less price-sensitive than indifferent or actively disengaged guests. They have a strong emotional attachment to the hotel brand they

${ }^{9}$ Source: www.clickz.com; "what-twitter-marketers-can-learn-from-jetblue-emirates-and-royal-dutch-airlines", Yuyu Chen, 2015

${ }^{10}$ Source: www.aol.com; "The secret behind how JetBlue has amassed such a loyal customer base", 2017

${ }^{11}$ Source: "Expectations Vs. Experience: The Good. The Bad. The Opportunity," Forrester Consulting, June 2016. Page 6. Link: https://www.accenture. com/t20160825T041338_w__us-en/_acnmedia/PDF-23/Accenture-Expectations

${ }^{12}$ Source: www.hospitalitynet.org; Opinion Article: “Price Impact on Guest Satisfaction”, Patrick Hellstrand, 2010 
TABLE 1. Feedback Channels - Airlines, Hospitality Industry

\begin{tabular}{|c|c|c|c|}
\hline No. & Feedback channels & Airlines & Hospitality \\
\hline 1. & Suggestion Boxes & $Y$ & $\mathrm{Y}$ \\
\hline 2. & Personal Emails & Y & $Y$ \\
\hline 3. & Telephone & Y & $\mathrm{Y}$ \\
\hline 4. & Mobile (App) & $\mathrm{Y}$ & $\mathrm{Y}$ \\
\hline 5. & Social Media & $Y$ & $Y$ \\
\hline 6. & One-on-One & Y & $Y$ \\
\hline 7. & Website & $Y$ & $Y$ \\
\hline 8. & Guest Comment cards & & $\mathrm{Y}$ \\
\hline 9. & $\begin{array}{l}\text { In-room/flight question- } \\
\text { naires }\end{array}$ & $Y$ & $Y$ \\
\hline 10. & Customer Surveys & $\mathrm{Y}$ & $\mathrm{Y}$ \\
\hline 11. & $\begin{array}{l}\text { Industry Market Research } \\
\text { Surveys }\end{array}$ & $Y$ & Y \\
\hline
\end{tabular}

visit most frequently and will promote it among friends, family and colleagues.

Research pointed out hotels use several means of gathering feedback from customers such as guest comment cards, in-room questionnaire, guest contact staff, telephone survey, internet survey, mail survey, and focus group interview (Birkby, 2004; Wirtz and Tomlin, 2000). Table 1 summarizes the various feedback channels used by hospitality and airlines industry. Hotels are also working hard to make sure they achieve a higher response rate on these surveys. Consequently, some questionnaires are now shorter, allowing guests to complete them in a few clicks, and sent to mobile devices to be filled out by customers. For example, The Denihan Hospitality Group uses a system created by Posmetrics $^{13}$ that rotates five questions on an iPad at the front desk. While post-stay surveys provide valuable insights into the guest experience and help hotels implement operational and service improvements, many hotels now employ an in-stay guest satisfaction survey solution to check in with guests while still on site. Loopon, a digital communications company, is offering a unified solution to monitor all guest communication a hotel needs in one easy-to-use tool that can be used to measure pre-stay, in-stay and post-stay guest experience.

Just as the case with the airline industry, social media presence is a key success factor in the hospitality industry. The online platforms, where its customers express their honest feedback and influence others' purchase decisions, offer an opportunity to understand their preferences and levers of choice. Among all the online platforms, TripAdvisor ${ }^{14}$ has emerged as the world's most popular community about travel, with more than five million registered users who visit the platform 30 million times per month on average (Banerjee and Chua, 2016).

Particularly, in this digital world, creating seamless digital and physical experiences for the customer has been a challenging endeavor for the industry.

The top industry trends that are driving growth and investment in technology include the fact that: (a) Customers spend more time online before making booking decisions, (b) Online reviews hold a lot of value for customers, and (c) Personalized experiences drive customer loyalty and retention. However, many hospitality companies lack the technology infrastructure that ties all areas of the business together to foster efficiency in its operations. A complete customer view across all channels to deliver seamless experiencesbefore they book, during their stay, and after they've left, is often missing. This leads to inconsistent interactions with individual customers across all touch points resulting in an overall patchy experience for the customer.

Providing premium service also requires a responsive and thoughtful staff that anticipates guest needs and customizes services. Additionally, treating guests with respect and courtesy, providing a sincere welcome and farewell on arrival and departure, resolving problems quickly and to the guests' satisfaction can help differentiate good service from bad. A hotel that trains employees to meet these service standards can gain a clear advantage in securing their customers' loyalty.

The gold standard for premium customer service in the industry is set by the luxury brand, The Ritz Carlton Hotel Company. The Gold Standards are the hotel's foundation and they encompass the values and philosophy by which it operates: The Credo, Motto, Three Steps of Service, Service Values, The 6th Diamond and The Employee Promise (as shown in Fig 7). For over three decades, Ritz has been measuring customer service success via a monthly Gallup poll. Customers are asked a series of carefully crafted

\footnotetext{
${ }^{13}$ Posmetrics is a market survey firm that provides feedback surveys to collect real-time results, and generate actionable recommendations.

${ }^{14}$ TripAdvisor, Inc. is an American travel and restaurant website company that shows hotel and restaurant reviews, accommodation bookings and other travel-related content;www.tripadvisor.com
} 


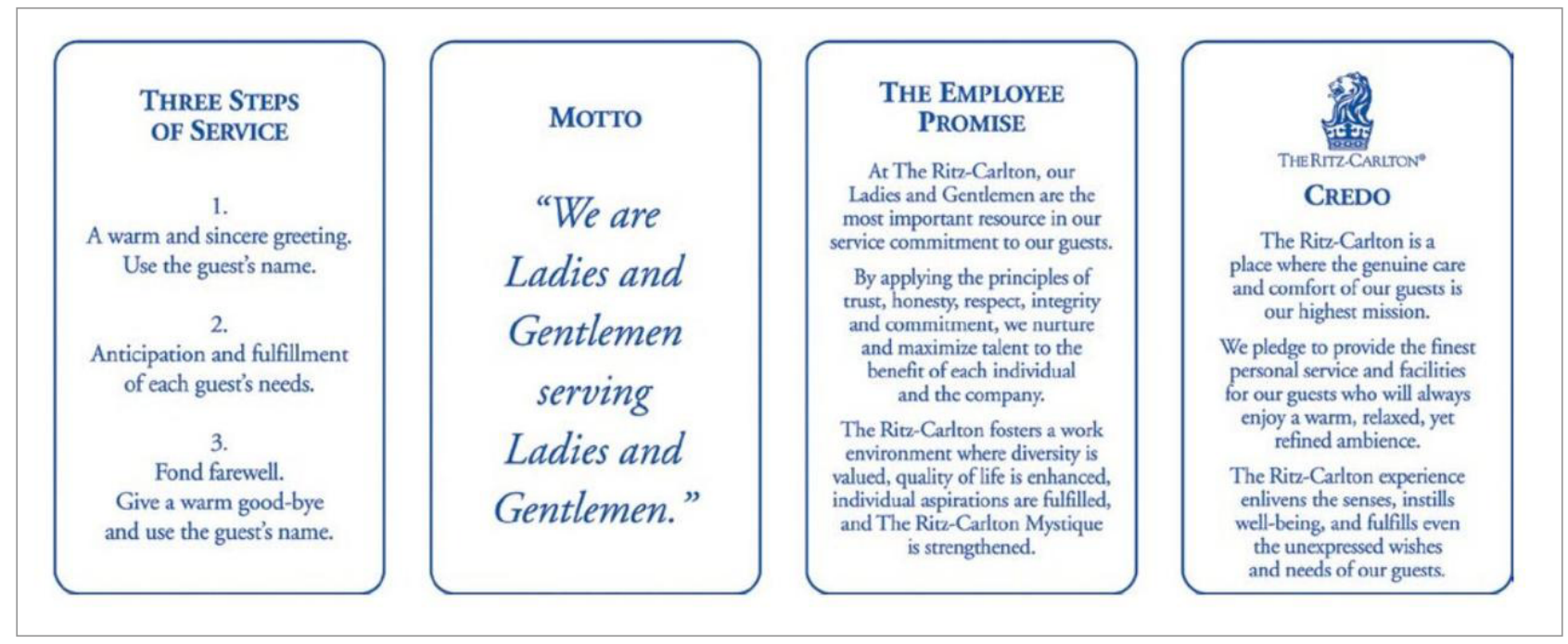

Source: www.ritzcarlton.com

open-ended and close-ended questions. Throughout the year, the questions are rotated in order to provide a broader understanding of the customers' needs and garner specific market research. The Gallup organization sends out the survey to 38 percent of guests that stayed the month before. It is a random selection with the expectation of an 8-10 percent response rate. The survey contains about 30 questions, including "How likely is that guest to recommend Ritz Carlton? Were they delighted and satisfied with their stay? If there was a problem, was the problem addressed?"

Ritz also prides itself on evaluating the survey results consistently and implementing changes in a timely manner. For instance, after 20 years of success in the hospitality business, a regular customer feedback exercise prompted Ritz to act and update its decades old customer service style. The hotel noticed some negative feedback on its surveys; guests felt the service appeared to be too robotic due to the stiffness of language choices and other prescribed aspects of their service interactions. In particular, the Ritz-Carlton's signature phrase, "my pleasure," was perceived to be overused and misused in the eyes of its customers. Upon receiving this feedback, Ritz acted on it by getting rid of the scripted phrases and using a more informal yet professional tone. More recently, the hotel has relaxed its employee dress code and grooming standards as well in a new strategy aimed at reinventing the brand and keeping it relevant. It is also making every property notably different from every other, and more in line with its local community's architectural, furnishings and culinary style, all due to the constant customer feedback it solicits. By evaluating customer feed- back consistently, this luxury hotel is staying relevant and ahead of the game.

\section{Implications for Health services}

Our main aim in this research was to determine which factors most strongly influence patient satisfaction, and how health systems must accurately understand the need for improved client-centered approaches to assess quality of care. We demonstrated this through the in-depth study of analogous service-oriented industries and the mechanisms they use to assess and act on customer feedback. As a result, three key takeaways emerge for health services to emulate:

1. Adopt CX approach to care delivery: Implementing a CX approach in health services can offer the missing dimensions of quality assessment in current monitoring efforts. The approach advocates the development of a deeper understanding of end-to-end client journey, from visit scheduling, admission process, and clinical exam followed by prescription and all the way to follow-up care. The client journey should be broken down further into discrete elements to identify the factors that can influence patient satisfaction at each step of the journey. By doing this, we can get a better handle on the role that price, service offerings, provider guidance, choice of brands, clinic ambiance and other factors play in determining how clients experience quality of care. In addition, we can get a better understanding of the elements that constitute their motivations for loy- 
alty by including both clinical and non-clinical factors. The customer journey mapping should be followed-up with in-depth qualitative research (e.g., focus groups/ one-on-one interviews and complaint logs) and quantitative research (e.g., large scale client/facility surveys) to isolate the factors that most strongly influence their satisfaction levels in conjunction with achieving desired health outcomes for the service providers. Further, the surveys should be designed with brevity in mind while capturing the critical measures of client experience. For example, a hospital that offers maternity and family planning services to a community could segment the needs of its clients based on their priorities at various stages of care - pregnancy, childbirth, and follow-up care including family planning needs. By understanding the needs that have the strongest impact on a new mother's satisfaction levels, the hospital can create positive experiences to attract and retain them.

Taking cue from the CX focus in the hospitality industry, healthcare providers engaged in facilitating medical tourism in both the developed and the developing worlds, are now designing superior experiences for their luxury clientele. For instance, at a Medical Center in Denver, delivery rooms have private bathrooms with Jacuzzi tubs, birth balls, rocking chairs, squat bars, and flat-screen TVs. After giving birth, mothers can stay at a luxury suite that comes with the services of a private chef. ${ }^{15}$ The Apollo Hospitals Group in India offers luxury suites to wealthier patients with personal attendants, interpreters and a well-stocked pantry with dining facilities. ${ }^{16}$ Hospital rooms in Dubai are now being designed to include touch-screen entertainment and communication systems that allow patients and companions to watch TV, play games, order meals, request extra pillows and call for an interpreter. ${ }^{17}$ While these services are clearly aimed at the wealthy clients, within the context of LMICs, tailoring unique sets of experiences (such as offering customized educational materials, creating a comfortable atmosphere to ease anxiety, using personalized yet non-judgmental language while interacting, to name a few) for a new versus a seasoned client can be the key differentiator in enhancing patient satisfaction, care continuation, and long-term loyalty for health service providers.

2. Empower providers with a quality mindset: Healthcare providers can be considered as the gatekeepers of patient satisfaction. Patient and provider satisfaction are inter-dependent to a great degree and many studies point to a strong correlation between provider engagement and positive outcomes. Improving patient experience increases provider satisfaction, and in turn improves their retention rates. Research from the Partnership for Public Service and Boston Consulting Group shows that improving staff engagement can boost patient satisfaction and other elements of the patient experience. ${ }^{18}$ And, studies reveal that hospitals that score high on patient care experience also do better on clinical outcomes. In a study of 927 US hospitals, it was noted that there is a strong association between patient experiences and clinical measures of quality and safety. Specifically, positive patient experiences were associated with lower infections due to good medical care (Issac et al., 2010).

When providers are coached and guided to think with the end goal of creating a positive experience for every client, successful health outcomes follow, and in turn they feel more valued and satisfied. Oklahoma University Medical Center is an example of how a hospital is learning valuable lessons on positive provider interactions from Ritz Carlton. After attending a training program at The Ritz-Carlton in 2008, Dr. Sawan, a plastic surgeon from the medical center, started an initiative titled "Service with a Smile" within his department, inspired by the Ritz's service principles. As part of the program, he reviewed customer care concepts with his staff on a weekly basis. As a result, his staff was more engaged with patients, and became more attentive to details like birthdays and preferred appointment times of patients, to name a few. In turn, his patients reciprocated by requesting staff assistants by name. By encouraging his staff to adopt a quality mindset and empowering them to take service decisions, positive staff interactions ensued that ultimately led to winning

\footnotetext{
${ }^{15}$ Source: https://ca.style.yahoo.com/blogs/parenting/most-luxurious-birthing-suites-america-160300064.html.

${ }^{16}$ Source: http://timesofindia.indiatimes.com/india/Some-hospitals-beat-five-star-hotels-in-luxury-and-tariffs-too/articleshow/34701940.cms

17 Source: http://www.thenational.ae/uae/dubai-health-authority-gives-patients-entertainment

18 The analysis, which looked at patient experience data from over 150 Department of Veterans Affairs (VA) medical centers between 2016 and 2018 , found that improving employee experience results in higher levels of patient satisfaction, improvements in call center efficiency, and reductions in nurse turnover. A one-point increase in employee engagement scores resulted in half-point improvements in patient satisfaction scores.
} 
and retaining more clients. In summary, it is important to note that there can be a positive compounding effect when health service organizations work on improving experience and engagement measures simultaneously.

3. Leverage data and technology to engage clients: In the evaluation of health services, Point of service feedback (POSF) has been widely used for patients to give feedback about their experiences either during or immediately after an episode of care, enabling problems to be assessed and addressed in a timely manner (Coulter et al., 2009; NHS England, 2013).The introduction of CX approach to health services emphasizes the need to leverage data and technology at every patient touch point to obtain detailed experience measures, including various interpersonal aspects of care. Technologies used to collect feedback have proliferated in the last decade and include paper-based or electronic questionnaires that are distributed by staff to patients. Further, healthcare organizations can gather data in a variety of ways including surveys, facility audits, comments and complaints, using mail, telephone, online or hand-held and other devices. Staff who work directly with patients can add to it and provide an insightful perspective. The data collected can be analyzed to study trends and identify repetitive experiences. Specifically, we can isolate problems that occur frequently and the types of clients that are most likely to experience it. Using a data-driven approach can help unearth valuable insights that are critical to providing quality patient experience.

Recently, it has been noted that the use of online portals for patient feedback collection is increasing among integrated healthcare services providers. For example, Apollo Hospitals, an Indian hospital chain, uses an online platform to collect inpatient and outpatient feedback and subsequently, benchmark the results among different Apollo hospitals, to create seamless patient experiences across their chain of hospitals. Online websites such as Best Hospital Advisor provide a unique platform that aims to help providers analyze the patient feedback data on a real time basis and design strategies to meet facility quality standards. These online feedback surveys use a standardized format such as the one prescribed by the Hospital Consumer Assessment of Healthcare Providers and Systems (HCAHPS) with the provision of customization for individual clients. For decades, FP clinics in the
FIGURE 8. Global Internet Users (\%)

\section{Internet users in emerging world are more frequent users of social networks compared with U.S. and Europe}

Regional medians of adult internet users or reported smartphone owners who use social networking sites

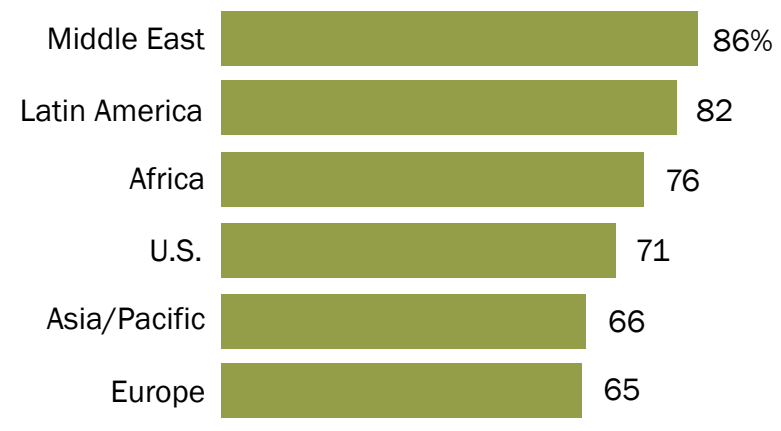

GLOBAL MEDIAN 76

Note: Based on those who say they use the internet at least occasionally (Q70) or report owning a smartphone (Q72). Russia and Ukraine not included in Europe median.

Source: Spring 2015 Global Attitudes survey. Q74. PEW RESEARCH CENTER

developing countries have used client exit interviews to measure clients' perspectives on quality. However, one of the main drawbacks of this method is 'recall bias' as clients cannot always be able to reliably reproduce finer aspects of their interactions with the providers. Also, following the approach used by the hospitality industry, the length of these surveys can be reduced to ensure that only the critical quality measures are captured in the questionnaire. As an enhancement to existing feedback methods, it may be useful to incorporate in-facility experience surveys, by either asking clients verbally at every touch point and recording their feedback via technology-enabled tools, akin to the in-stay surveys used by hotels. By staggering the lengthy exit survey throughout the visit, we can reduce overwhelm for clients that have already endured long commutes and wait times to reach the facility and receive care. With increased mobile and internet use in the developing world (see Fig. 8), these clinics can further benefit from using different technology platforms such as the use of tailored mobile surveys or online websites to gather meaningful and actionable data. 


\section{Conclusions}

Our research, being of an exploratory nature, offers many opportunities for future extensions, both in terms of understanding feasibility of implementation along with the inherent limitations and applicability in the settings of interest. Recognizing that clients' rights to quality services remains the primary focus of global FP programs, we delved deeper into understanding best practices from other industries that can be adopted and reused to fit the needs of health services.

First, while we have expounded the possibility of using a CX approach to health services, it may be critical to understand the extent to which it can be implemented within the context of health services. Limitations in the form of funds shortages, lack of appropriate training infrastructure, overworked staff and the associated burnout, to name a few, can present themselves as barriers to successful adoption in resource constrained settings. Further, any new concept takes time to grasp and consistency is key to realize the desired change. Investment of time, effort and money can be key in the initial years to create long lasting impact. While very nuanced lessons can be learned from Airlines and Hospitality industries in understanding client satisfaction, the heavy use of technology to track and act on the feedback cannot be easily adapted in the context of health programs serving LMICs, owing to the lack of advanced technology infrastructure. At a minimum, client journey mapping can be institutionalized to identify pain points and design effective provider interaction mechanisms to address them proactively.

Second, our study offers the opportunity to refine and validate our understanding around managing provider satisfaction as a means to improve client satisfaction. For example, providing adequate training to providers regarding the handling of client relations including treating them with dignity, respect and ensuring their privacy and confidentiality, can help empower the providers to offer better service quality. Further, entrusting them with the responsibility of "actively listening" to their clients' feedback can make them feel more valued. Keeping this in mind, training strategies should highlight the enhanced role of providers in client satisfaction without the addition of workload that might interfere with their core job of care delivery.
Third, we turn our attention to the rising use of social media for health-related purposes in LMICs by a variety of stakeholders including patients, healthcare professionals and the governments (Hagg et al., 2018). Governmental and non-governmental organizations have been the key content creators on social media for health in LMICs, while end-users are typically young or marginalized populations. We understand that Twitter, the widely used social media platform, has the ability to facilitate disease surveillance, mass communication, health education, knowledge translation, and collaboration among health providers, with its recent role in the Ebola outbreak. Following along the lines of JetBlue Airlines' social media strategy, we can propose the use of these platforms to engage with young adolescents and create conversations around quality of health services. Announcing promotion campaigns, games and contests via twitter can be an attractive way to get them to engage in health campaigns while creating awareness at the same time.

In conclusion, quality efforts in health services can benefit substantially from refining provider training materials with $\mathrm{CX}$ principles, replacing lengthy exit surveys with short experience surveys and creating a client-centered culture by putting patients first and at the heart of the feedback system. 


\section{References}

Ali, M.M. 2001. "Quality of care and contraceptive pill discontinuation in rural Egypt," Journal of Biosocial Science 33(2): 161-172.

Arends-Kuenning M. and F.L. Kessy. 2007. "The impact of demand factors, quality of care and access to facilities on contraceptive use in Tanzania," Journal of Biosocial Science 39(1): 1-26.

Banerjee, S. and A. Y. Chua. 2016. In search of patterns among travellers' hotel ratings in TripAdvisor. Tourism Management, 53: $125-131$.

Berry, L.L. and A. Parasuraman. 1997. "Listening to the customer - the concept of a service-quality information system," Sloan Management Review 38(3): 65-76.

Birkby, B. 2004. Standing in the customers' shoes. The British Journal of Administrative Management, 41: 26-28.

Bruce, J. 1990. "Fundamental elements of the quality of care: A simple framework," Studies in Family Planning 21(2): 61-91.

Chase R. and S. Dasu. 2013. The Customer Service Solution: Managing Emotions, Trust, and Control to Win Your Customer's Business. Columbus, $\mathrm{OH}$ : McGraw-Hill Education.

Clayton, E. and A. Hilz. 2015. 2015 Aviation Trends. http://www. strategyand.pwc.com/perspectives/2015-aviation-trends.

Clay-Williams R. and L. Colligan. 2015. "Back to basics: Checklists in aviation and healthcare," BMJ Quality \& Safety 24: 428-431.

Coulter, A., R. Fitzpatrick, and J. Cornwell. 2009. The Point of Care. Measures of Patients' Experience in Hospital: Purpose, Methods and Uses. London: The Kings Fund. https://www.kingsfund.org.uk/ sites/default/files/Point-of-Care-Measures-of-patients-experiencein-hospital-Kings-Fund-July-2009_0.pdf.

DeVine, J. and Keith Gilson. 2010. "Using behavioral science to improve the customer experience." https://www.mckinsey.com/ business-functions/operations/our-insights/using-behavioralscience-to-improve-the-customer-experience. Accessed 20 June 2019.

Erickson, G.S. and D.W. Eckrich. 2001. "Consumer affairs responses to unsolicited consumer compliments," Journal of Marketing Management 17(3): 321-340.

Gordon S., P. Mendenhall, and B. O'Connor. 2013. Beyond the Checklist: What Else Health Care Can Learn from Aviation Teamwork and Safety. Ithaca, NY: Cornell University Press.
Guttmacher Institute. 2017. "Adding It Up: The Costs and Benefits of Investing in Sexual and Reproductive Health 2017." Fact sheet. New York: Guttmacher Institute.

Hagg, E., V.S. Dahinten, and L.M Currie. 2018. "The emerging use of social media for health-related purposes in low and middleincome countries: A scoping review," International Journal of Medical Informatics 115: 92-105.

Isaac, T., A.M. Zaslavsky, P.D. Cleary, and B.E. Landon. 2010. “The Relationship between Patients' Perception of Care and Measures of Hospital Quality and Safety," Health Services Research.

Jain, A. and K. Hardee. 2018. "Revising the FP Quality of Care Framework in the context of rights-based family planning," Studies in Family Planning 49(2): 171-179.

Mensch B., M. Arends-Kuenning, and A. Jain. 1996. "The impact of the quality of family planning services on contraceptive use in Peru," Studies in Family Planning 27(2): 59-75.

NHS England. 2013. "Putting Patients First. The NHS England Business Plan for 2013/14-2015/16.” https://www.england.nhs. uk/publication/putting-patients-first-nhs-england-business-planfor-201314-201516/. Accessed 20 June 2019.

RamaRao S., M. Lacuesta, M. Costello, B. Pangolibay, and H. Jones. 2003. "The link between quality of care and contraceptive use," International Family Planning Perspectives 29(2): 76-83.

Sampson, S.E. 1996. "Ramifications of monitoring service quality through passively solicited customer feedback," Decision Sciences 27(4): 601-622.

Thomas E. and R. Helmreich. 2002. "Will airline safety models work in healthcare?" in Rosenthal, M. and K. Sutcliffe (eds), Medical Error: What Do We Know? What Do We Do? San Francisco: Jossey-Bass, pp. 217-234.

Tumlinson, Katherine. 2016. "Measuring quality of care: A review of previously used methodologies and indicators." Working Paper Two of the Measuring and Monitoring Quality of Services and Quality of Care Project. New York: Population Council.

Wirtz, J. and M. Tomlin. 2000. Institutionalising customer-driven learning through fully integrated customer feedback systems. Managing Service Quality 10(4): 205-214. 